\section{ASTRONOMIA:}

\section{UMA}

\section{EXPERIÊNCIA EM}

QUE MULHERES

\section{ATUAM COMO \\ PROTAGONISTAS}

\author{
Elza Ferreira Santos[*] \\ José Osman dos Santos[**] \\ Ieda Fraga Santos[***]
}

[*] Doutora em Educação - Instituro Federal de Sergipe - IFS elzasantos@gmail.com

[**] Doutor em Física - Instituto Federal de Sergipe - IFS osmansantos@ig.com.br

[***] Mestranda em Educação - Instituição Federal de Sergipe - IFS iedafragaufs@gmail.com

\section{Resumo}

A astronomia é uma ciência que agrega amadores e pesquisadores profissionais. Tanto de um modo quanto do outro ela tem atraído mais homens do que mulheres no Brasil e no mundo. Sua aproximação com a física e com a matemática explica, possivelmente, o grande número de adeptos masculinos. Porém, em Sergipe, a sociedade de estudos astronômicos denominada SEASE tem mostrado que a astronomia pode seduzir mulheres e fazer delas cientistas. $\mathrm{Na}$ SEASE, elas são estudiosas e também ocupam cargos de liderança. Considerando a importância desta ciência, este texto oferece uma breve apresentação das pioneiras na astronomia e um relato da formação da SEASE e da organização de um dos maiores congressos de astronomia do país, o $15^{\circ}$ Encontro de Astronomia do Nordeste. Assim, intenciona mostrar que quando mulheres e homens têm as mesmas oportunidades de aprender e de gostar de matemática, elas podem fazer a escolha por uma carreira científicotecnológica. Também intenciona visibilizar histórias de mulheres inseridas nas carreiras científico-tecnológicas, a fim de se alcançar a equidade de gênero nas instituições de ensino superior e órgãos de pesquisa, especialmente nas ciências duras.

Palavras-chave: Astronomia, Mulheres, Lideranca. Gênero. 
"Men need experience working with women as their peers in order to learn how to relate to female astronomers as astronomers rather than as females." 1

(CLAYTON, 1992, p. 31)

As mulheres continuam distanciadas das áreas das ciências exatas, das diversas engenharias, ou seja, das áreas que costumam exigir aquisição dos saberes matemáticos, espaciais e tecnológicos (CARVALHO \& RABAY, 2013; LOMBARDI, 2005). Nos cursos relacionados ao que se convencionou chamar de ciências duras, elas entram nas universidades e nos institutos superiores em pequeno número se comparado aos homens, e ao concluírem o curso superior não há nenhuma garantia de que exercerão as profissões referentes aos saberes aprendidos na graduação.

Conhecem-se jovens engenheiras, por exemplo, que depois de formadas experimentam uma função no mercado de trabalho e recuam voltando para os centros de pesquisa, para a docência, para algum trabalho que as tire do chão da fábrica, da obra ou da empresa. No caso da física, muitas mulheres que iniciam o curso acabam por desistir: "Uma proporção maior de mulheres que de homens abandona a física em cada estágio da carreira" (AGRELLO \& GARG, 2009, p. 1305-1). As razões são diversas e envolvem tanto aspectos sociais, quanto psíquicos. Estudos apontam para a segregação nos cursos superiores e tecnológicos e, consequentemente, nas carreiras em que se empregam conhecimentos matemáticos e físicos (AGRELLO \& GARG, 2009; CARVALHO, 2006).

Este relato de experiência destaca uma área - a Astronomia - que também é reduto masculino, mas em que paulatinamente as mulheres têm se inserido e, a partir do lugar que ocupam, têm combatido a invisibilidade feminina. No Brasil e em vários países ocidentais, as mulheres têm sido responsáveis por grandes avanços na Astronomia (VIEGAS, 2014). No Nordeste brasileiro, na Sociedade de Estudos Astronômicos de Sergipe (SEASE), apesar do pequeno número de mulheres, são elas que comandam a sociedade e, recentemente, responderam pela organização do $15^{\circ}$ Encontro de Astronomia do Nordeste (EANE) realizado em junho de 2015 .

\footnotetext{
1 "Homens necessitam experimentar trabalhar com mulheres como pares para aprenderem como se relacionar com astrônomas mulheres como astrônomas e não como mulheres” (tradução das autoras).
} 
Entretanto, essa situação de comando - liderança - não pode ser entendida como avanço em sua totalidade, mas como um caso em que mais uma vez se confirma ser a trajetória de mulheres nas carreiras acadêmicas erguida por processos de inclusão e exclusão, avanços e recuos (CARVALHO, 2006).

\title{
Sobre Astronomia
}

"A astronomia é considerada por muitos cientistas e filósofos o primeiro conhecimento humano organizado (...) Os primeiros passos do homem pré-histórico neste planeta foram dados sempre com os olhos contemplando e buscando desvendar o céu" (AMARAL, 2008, p. 14). Tal como o homem pré-histórico, sucessivas gerações olham para os céus para contar as estrelas, buscar a finitude do azul, entender de onde vêm ou indagar se existe vida na lua ou nos planetas.

Contudo, não é tão simples falar de astronomia, tampouco explicar para alguém que um astro é seu objeto de estudo. Ainda hoje, a perplexidade e a confusão são enormes:

\begin{abstract}
Quando falo que sou astrônoma geralmente as pessoas acham interessante, mas muitos confundem com astrologia e aí eu fico uma fera (risos). Se me pedirem para fazer o horóscopo, sou capaz de deixar a pessoa falando sozinha (...) Acho que a situação mais interessante ocorreu quando recebi o prêmio Diáspora Brasil e fui apresentada como "Astrofísica Extragaláctica". Nunca tinha percebido que as pessoas arregalavam os olhos quando me apresentavam assim. (MELLO, 2015, p. 1).
\end{abstract}

A fala acima foi concedida por Duília Mello em uma entrevista. Ela é uma renomada astrofísica brasileira que trabalha na National Aeronautics and Space Administration (NASA) e por meio de sua declaração pode-se perceber o quão surpreendente é dizer algo relacionado à astronomia.

Em Sergipe, durante o EANE, esteve outra pesquisadora anglo-brasileira - Rosaly Lopes - que também trabalha na NASA. Ela concedeu diversas entrevistas. Uma delas foi na rádio Ilha FM em 4 de junho de 2015 e, como foi uma entrevista aberta ao público, surgiram perguntas relacionadas a aspectos religiosos, como por exemplo, será que os astrônomos não estavam querendo desvendar os segredos de Deus, ou perguntas relacionadas à astrologia. A 
entrevistada não demonstrou aborrecimento nem surpresa; disse, depois, que tais perguntas eram comuns.

Não se sabe até que ponto essas confusões podem atrapalhar a formação de mais astrônomos, mas certamente quanto mais houver popularização da ciência, mais haverá adeptos. Há, no Brasil, poucos cursos de graduação em astronomia. A Universidade Federal do Rio de Janeiro (UFRJ) oferece há 50 anos e em 2009 a Universidade de São Paulo (USP) passou a ofertar o bacharelado em astronomia (STEINER, 2009). A quantidade pequena dos cursos não significa que os estudos no país sejam principiantes ou desacreditados. Ao contrário, há em outras instituições o programa de pós-graduação em astronomia ou uma habilitação. Por exemplo, tanto na USP como na Universidade Federal de Sergipe (UFS) e na Universidade Federal do Rio Grande do Sul (UFRGS), existe a opção de habilitar-se em astronomia no bacharelado em física. Além disso, há diversos grupos de pesquisa e coletivos de interessados em astronomia espalhados pelo Brasil.

\begin{abstract}
Os maiores grupos de pesquisa em astronomia estão concentrados na USP e nas universidades federais - como UFRGS, UFRJ e UFRN — assim como nos institutos do Ministério de Ciência e Tecnologia (MCT), Observatório Nacional e Inpe. Todos eles mantêm programas de pós-graduação em nível de mestrado e doutorado. (STEINER, 2009, p. 47).
\end{abstract}

A astronomia é uma ciência, tanto na América quanto na Europa, construída por muitos homens e poucas mulheres. Mas elas estiveram presentes desde os primórdios. Registra-se como primeira estudiosa a sacerdotisa da Babilônia Hedu'Anna. Há 4000 anos ela ajudou "a decifrar as estrelas e desenvolver os calendários, tornando-se símbolo e referência importante para astrônomos e matemáticos" (GARCIA, 2006). Outra foi Hipatia, uma grega que vivia em Alexandria no século quarto e estudava astronomia, matemática e filosofia. Assim, ao longo da história vão surgindo nomes de mulheres que contribuíram com a astronomia, porém nem sempre reconhecidas, pois "often women astronomers were assistants to their fathers, husbands, or brothers; such collaboration makes it all too easy to label their work as not particularly original" (DOBSON \& BRACHER, 1992, p. 5) ${ }^{2}$.

\footnotetext{
2 “frequentemente as mulheres astrônomas eram assistentes de seus pais, maridos ou irmãos; tal colaboração torna demasiado fácil rotular o trabalhos delas como não particularmente original" (tradução das autoras).
} 
Um episódio curioso na história da astronomia é que o grande desenvolvimento dessa ciência se dá com mulheres nos Estados Unidos. O astrônomo Edward Charles Pickering, quando em 1877 se tornou diretor do Harvard College Observatory (OCO), cercou-se de uma equipe feminina de cerca de 80 mulheres. Dentre as razões para que isso ocorresse destacavam-se duas, a saber: pagar as mulheres era menos custoso do que pagar aos homens e as tarefas no laboratório eram extremamente repetitivas. As mulheres recebiam em torno de $50 \%$ do que os homens receberiam pelas mesmas tarefas (MCDERMOTT, 2014).

Decepcionado com a falta de concentração e incapacidade dos homens para dar atenção aos detalhes, Pickering acabou por convocar para auxiliá-lo na empreitada uma numerosa equipe de mulheres, que, para ele, eram mais responsáveis, pontuais e meticulosas. (MANNARINO, 2011).

Acrescente-se o fato de ser Pickering um sufragista e reconhecer que havia uma nova geração de mulheres estudiosas. A equipe feminina do laboratório de Harvard ficou conhecida como o "harém de Pickering". Entre as mais ilustres, encontravam-se Williamina Fleming (1857-1911), Antonia Maury (1866-1952) e Annie Cannon (1863-1941). Eram as três astrônomas responsáveis pelos novos sistemas de classificação das estrelas utilizados até hoje. Cannon, por exemplo, foi a primeira mulher a receber um doutorado honorário da Universidade de Oxford, a primeira mulher a receber um título de membro da Sociedade Astronômica Americana e a primeira mulher a receber a Medalha de Ouro Draper, da Academia Americana de Ciências. Ela era quase surda, mas tinha uma aguçada visão.

Outra que se tornou famosa foi Henrietta Swan Leavitt (1868-1921). Nomeada por Pickering como chefe do departamento de fotometria estelar e de classificação estelar, foi quem estabeleceu a relação período-luminosidade das Cefeídas. Trabalhou cerca de sete anos sem receber nenhum salário, assoberbada por problemas de saúde e pelas suas obrigações domésticas (MANNARINO, 2011). Ainda hoje, o casamento, a maternidade e os afazeres domésticos constituem-se empecilhos para o progresso na carreira científica para as mulheres (LIMA, 2013).

$\mathrm{O}$ fato de uma equipe de astrônomas ser reconhecida como um "harém" mostra o quanto esse grupo era destratado pelos seus pares masculinos (MCDERMOTT, 2014). A palavra harém é de origem árabe e significa lugar proibido. Significa um grupo de mulheres que habitam e compartilham uma casa, vivendo sob as regras de um casamento poligâmico. A 
denominação acentua o dito anteriormente - as mulheres astrônomas dificilmente eram valorizadas como profissionais. Por um lado, "harém" denota preconceito, ilegalidade e, quase sempre, semanticamente associa-se pejorativamente a sexo. Entretanto, por outro lado, não se deve negar a ousadia que essas mulheres tiveram.

No Brasil, há registros de estudos astronômicos na cultura indígena, ou seja, bem antes dos europeus aqui chegarem e colonizarem, os índios se valiam das estrelas para guiar suas plantações, por exemplo. Os estudos sistemáticos em astronomia se iniciaram em 1827 com a criação do Observatório Nacional (ON) e o grande impulso veio entre as décadas de 1960 e 70 em virtude do crescimento de grupos de estudo e dos primeiros cursos de pós-graduação.

A mulher brasileira pioneira nos estudos astronômicos formais foi Yedda Ferraz Pereira, nascida no Rio de Janeiro e formada em engenharia civil. Ela entrou no ON, em 1948, convidada pelo astrônomo-chefe Domingos Costa e em 1955 foi efetivada por meio de concurso público. Mas em 1962 pediu exoneração do cargo a fim de se dedicar aos cuidados dos filhos e da casa e, posteriormente, do pai. Esse fato da vida da pioneira brasileira não é incomum. Aliás, o reduzido número de mulheres na astronomia não é um fato isolado, faz parte de um problema social associado ao preconceito de gênero. As mulheres ainda não estão em pé de igualdade com os homens no mundo do trabalho. Muitas empresas preferem contratar homens casados e mulheres solteiras, haja vista que as mulheres casadas arcam com um fardo enorme (CLAYTON, 1992).

Em 1974 foi criada a Sociedade Astronômica Brasileira com a presença de 43 homens e cinco mulheres (VIEGAS, 2014). Dessas, a única docente era Sueli M. Viegas-Aldrovandi, do Instituto de Astronomia, Geofísica e Ciências Atmosféricas da USP (IAG), sendo as outras quatro alunas de pós-graduação: Massae Sato, do IAG, Liliana Piazza, Maria Alcina Braz e Maria Helena Paes de Barros do Centro de Rádio-Astronomia e Astrofísica Mackenzie (CRAAM). Cinco parece pouco, mas se considerarmos que antes de serem astrônomas tinham uma formação em engenharia veremos que o percentual para a época é significativo.

Atualmente, o número de brasileiras na astronomia é expressivo. Entre os países que fazem parte da International Astronomical Union (IAU), o Brasil se classifica entre os dez 
primeiros com percentual acima de $20 \%$ de participação feminina na astronomia. Entre associados brasileiros do IAU, as astrônomas brasileiras compõem 22,75\% (CESARSKY \& WALKER, 2010).

Ter nomes de brasileiros e brasileiras astrônomos divulgados no circuito acadêmico e na mídia desperta muito a atenção e certamente é um atrativo para que meninos e meninas desejem seguir a carreira. No caso de mulheres, ultimamente podemos citar três delas que desfrutam de reconhecimento. A primeira é Rosaly M. C. Lopes-Gautier, formada na Inglaterra e conhecida por seu trabalho em Geologia Planetária no Laboratório de Propulsão a Jato (JPL) da NASA, onde ingressou em 1989. Ela esteve no $15^{\circ}$ Encontro de Astronomia do Nordeste apresentando a palestra Titã, a lua misteriosa de Saturno. Foi uma das palestras mais concorridas e ovacionadas.

A segunda é Beatriz Barbuy que, após estagiar no Observatório de Meudon, doutorou-se pela Universidade de Paris, em 1982, dedicando-se posteriormente à astrofísica estelar, em particular ao cálculo dos espectros moleculares nas estrelas, no Instituto Astronômico e Geofísico da Universidade de São Paulo. Em seus estudos das estrelas de fraco teor metálico, com o objetivo de explorar a formação da Via-Láctea, Beatriz fez valiosas contribuições com relação às estrelas do núcleo da nossa Galáxia.

Como pesquisadora e professora na USP, teve um importante papel no desenvolvimento da astrofísica no Brasil.

A terceira é Duília de Mello, graduada em astronomia pela UFRJ e doutora pela USP. É professora de física e astronomia na Universidade Católica de Washington e pesquisadora associada do Goddard Space Flight Center, da NASA. Entre suas principais descobertas estão a Supernova 1997D e as Bolhas Azuis.

Todas elas reconhecem o valor dos estudos produzidos por mulheres na Astronomia. E, por isso, além de fazerem ciência, desenvolvem trabalhos de popularização da ciência. Um dos objetivos desses trabalhos é atrair meninos e meninas a conhecerem essa área de saber. 


\section{Sobre a SEASE}

A Sociedade de Estudos Astronômicos de Sergipe, doravante denominada SEASE, cumpre a função pioneira de desenvolver o conhecimento astronômico no âmbito prático e teórico e de democratizar a informação e pesquisa em Astronomia, gerando, pedagogicamente, potencial científico no estado. Conforme o art. 3o do Estatuto da SEASE, constituem seus objetivos: “a) Realizar estudos sistemáticos teórico/práticos e observacionais; b) Divulgar estes estudos na comunidade acadêmica, escolas e comunidade em geral; c) Desenvolver materiais científicos e pedagógicos para pesquisa e ensino da astronomia" (SEASE, 2011).

A SEASE nasceu da ideia de um grupo de entusiastas da astronomia da Universidade Federal de Sergipe, especificamente no âmbito do Departamento de Física, em 1991. A sociedade tinha como nome Grupo de Astronomia Johannes Kepler até 2001, mas em 2002 o grupo sofreu alteração de nome e foi institucionalizado. Da época de sua fundação até hoje muitas pessoas se tornaram membros, algumas saíram e outras entraram. Hoje, dentre os que estavam na sua fundação, permanecem apenas dois homens, um formado em pedagogia e outro em história.

A SEASE é uma associação de indivíduos em torno de interesses em comum, não econômicos, ligada à observação sistemática em astronomia com o objetivo de fornecer subsídios para a pesquisa científica na área. Nesse sentido, desenvolve a astronomia teórica e observacional. A astronomia teórica busca explicações e teorizações a partir de dados observacionais. A astronomia observacional busca e registra estes dados de forma sistemática. A sociedade compõe-se não só de amadores mas também de estudiosos de astronomia, em especial, estudantes que cursam física com habilitação em astronomia na UFS. Assim, inclui-se na lista de associações que prestam "uma valiosa contribuição local para a motivação, popularização e o ensino da astronomia, suprimindo carências específicas nesta área" (LANGHI \& NARDI, 2009, p. 4402-5).

A SEASE desenvolve eventos para popularização e desenvolvimento da astronomia no 
estado de Sergipe, tais como as regulares observações com telescópio, abertas ao público, e palestras didáticas aos alunos de escolas da capital e do interior, da rede pública e privada de ensino, assim como promoção de minicursos de formação complementar de professores. Anualmente, organiza os eventos Olhar de Minerva (voltados à participação feminina no desenvolvimento científico), o Luau Astronômico (atendendo a perguntas astronômicas) e a Semana de Estudos Astronômicos Sergipanos. Por fim, a Sociedade participa das edições anuais da Semana Nacional de Ciência e Tecnologia organizada pelos Ministérios de Educação (MEC) e de Ciência e Tecnologia (MCT).

Tal como a área da astronomia, a SEASE é uma sociedade majoritariamente masculina. Atualmente conta com 50 membros, dentre eles, 32\% são mulheres. É um índice considerado alto tendo em vista que a astronomia está próxima da física e da matemática, áreas em que a participação feminina ainda é pequena. Como mencionado, astronomia é uma habilitação vinculada ao curso de bacharelado em física na UFS.

A despeito da histórica participação das mulheres na física, atualmente é pequeno o número delas nessa área e isso implica a redução de mulheres com formação acadêmica em astronomia ou em astrofísica. Por quê? Os estudos têm apontado que as mulheres "estão concentradas nas ciências soft: as ciências da vida e do comportamento e as ciências sociais. Poucas mulheres são encontradas nas ciências hard ou físicas" (SCHIEBINGER, 2001, p. 78). Essa realidade está presente no mundo:

O estudo do American Institute of Physics (AIP) demonstra que o problema da pouca participação das mulheres no campo da física não se restringe aos Estados Unidos: na maioria dos países, menos de $20 \%$ dos títulos de doutorado em física são concedidos a pesquisadores do sexo feminino. No que diz respeito à titulação no nível de graduação, pode surpreender alguns leitores a informação de que o país com maior porcentagem (39\%) de diplomas de graduação em física concedidos a mulheres é a Turquia (AGRELLO \& GARG, 2009, p. 1305-4).

Entre as mulheres da SEASE, apenas uma é da área da educação. Todas as demais pertencem às ciências duras - física, engenharia elétrica, licenciatura em química. Há que se registrar a presença de alunas do $3^{\circ}$ ano do ensino médio com intenção em prestar vestibular para física. O perfil acadêmico dos homens é praticamente o mesmo das mulheres, com exceção dos dois fundadores. Enfim, o acesso à astronomia ocorre por meio da matemática e da física, 
principalmente, e a representação de mulheres nos cursos superiores dessas áreas é mínima. Segundo Carvalho e Rabay (2013, p. 22),

mesmo nas licenciaturas em física e matemática há mais homens do que no Bacharelado [na instituição pesquisada pelas autoras]. Esse fato sugere que o magistério dessas duas disciplinas não se feminizou nem tende a se feminizar, portanto, os/as estudantes de nível médio continuarão a se defrontar com modelos de papel docente (role models) predominantemente do sexo masculino.

Logo, faltam modelos de profissionais mulheres nas ciências duras. Em se tratando especificamente de física, quanto à porcentagem de mulheres e de homens entre os docentes lotados em algumas universidades brasileiras, os índices permanecem baixos:

A participação das mulheres atinge cerca de $25 \%$ em alguns casos, como na Universidade de São Paulo (USP) e na Universidade Federal do Rio Grande do Sul (UFRGS), que estão em áreas mais desenvolvidas economicamente. Mas o desenvolvimento econômico não é o único fator determinante da participação das mulheres no meio acadêmico. Na própria Universidade de Brasilia (UnB), localizada na capital federal, onde a renda per capta é uma das mais elevadas do país, as mulheres são apenas $18 \%$ do total de professores. E em universidades situadas em estados mais pobres, como a Universidade Federal do Espírito Santo (UFES), a porcentagem de mulheres é ainda inferior, abaixo de 5\% (AGRELLO \& GARG, 2009, p. 1305-3).

Em Sergipe, na Universidade Federal, o departamento de física é composto por 40 docentes e desses apenas seis são mulheres. Seu corpo técnico compõe-se de nove técnicos, sendo que apenas três são mulheres, entre as quais uma ocupa a função de secretária do departamento. No Instituto Federal, em todos os campi, não há mulheres professoras de física. Essa realidade é comum no Brasil e no mundo:

Women's representation among faculty in STEM ${ }^{3}$ disciplines has increased over time, but women remain underrepresented among tenured faculty. In the fields of physics, engineering, and computer science, women are scarce at every level, so attracting and retaining female faculty is critical. (TROWER, 2010, p. 68) ${ }^{4}$

O fato é que são poucas meninas a desfrutarem valores positivos em relação a essa área, o que, consequentemente, afeta a participação delas nas carreiras que exigem expertise em matemática e/ou em conhecimento espacial.

3 Science, Technology, Engineering and Mathematics (ciência natural, tecnologia, engenharia e matemática) corresponde à sigla STEM.

4 “A representação de mulheres entre docentes em disciplinas de STEM cresceu ao longo do tempo, porém as mulheres continuam sub-representadas entre os docentes efetivos. No campo da física, engenharia e ciência da computação, as mulheres são escassas em todos os níveis, portanto atrair e reter docentes mulheres é crítico" (tradução das autoras). 
Porém, a administração da SEASE, em princípio surpreende, pois se compõe de uma presidente, uma tesoureira e uma secretária, todas estudantes do curso de Física, com habilitação em Astronomia. Apenas a vice-presidência é ocupada por um homem. Isso é um avanço. À frente da Sociedade e olhando para o futuro, elas investem em eventos nos quais se discute o papel da mulher na ciência (Projeto Minerva). Sabem que filhos e afazeres domésticos poderão atrapalhar a carreira acadêmica, mas não conseguem vislumbrar que isso venha a ocorrer com elas. Todas, com exceção de uma, são solteiras e não possuem filhos. Em casa, vivem o privilégio de serem apenas estudantes, então pouco ou nada contribuem com os serviços domésticos nem exercem outra ocupação. Ou seja, desconhecem na prática que "ser cientista, esposa e mãe é uma carga em uma sociedade que espera que as mulheres, mais do que os homens, ponham a família à frente da carreira" (SCHIEBINGER, 2001, p. 182).

Nas reuniões da SEASE, a palavra é da presidente e da tesoureira, mas se vê constantemente recorrerem à palavra de quatro homens, os dois fundadores, o ex-presidente da SEASE e um professor do departamento de física da UFS. Esses homens, pelo papel de destaque que possuem, pois são formados, mais velhos e mais experientes, são uma espécie de gurus. Entretanto, isso não significa ausência de conflitos. Quando os conflitos aparecem, a decisão é da administração. Ao menos foi assim que essa administração respondeu pela organização do EANE.

\section{Sobre o $15^{\circ}$ EANE}

O primeiro encontro de astronomia do nordeste ocorreu no período de 29 a 31 de dezembro de 1975 na cidade de Fortaleza no estado do Ceará, denominado então $1^{\circ}$ Colóquio de Astronomia do Nordeste. Só a partir de 1978 é que passou a ser chamado de Encontro de Astronomia do Nordeste (EANE).

O $15^{\circ}$ EANE foi realizado em São Cristóvão - SE, nos dias 4, 5 e 6 de junho de 2015. A abertura foi no dia 4 de junho no Auditório da Reitoria da UFS. O objetivo foi promover um momento de formação, geração e divulgação de conhecimentos em astronomia a partir da integração entre os grupos de astronomia da região nordeste, professores de ciências do ensino 
fundamental e médio, estudantes de graduação e pós-graduação em ciências e pessoas interessadas em astronomia de forma geral. Tal integração visou divulgar projetos de ensino e pesquisa em astronomia e ampliar suas ações.

O trabalho de organização do $15^{\circ}$ EANE foi dividido em três etapas. A primeira compreendeu a parte de planejamento, elaboração e apresentação do seu projeto. Nesta etapa foram convidadas instituições de ensino, entidades afins e outros para tornarem-se parceiros na realização do evento. Foram feitos, também, os primeiros contatos com os palestrantes convidados e associações de astronomia da região nordeste, seguidos da construção de um site para o evento, além de confecção e envio de cartazes e folders para divulgação. Entre as instituições de ensino, prontamente atenderam ao convite a Universidade Federal de Sergipe (UFS), o Instituto Federal de Sergipe (IFS) e a Casa de Ciência e Tecnologia de Aracaju (CCTECA).

Toda essa etapa foi dirigida praticamente pelas mulheres da SEASE. O contato com os/as palestrantes - entre os quais havia uma internacional, Rosaly Lopes, já mencionada, única mulher entre os oito palestrantes - foi feito pelas estudantes de física, dirigentes da SEASE, com grande entusiasmo.

O contato com representantes das instituições de ensino - IFS, Campus Aracaju e UFS, Campus São Cristóvão - e de entidades como CCTECA, Central Única dos Trabalhadores (CUT) e Sindicato dos Trabalhadores em Educação Básica do Estado de Sergipe (SINTESE) foi mediado por professores. Nas primeiras, havia diretores; nas últimas, havia mulheres como presidentes. Curiosamente, o contato com as presidentes foi informal e o apoio foi irrestrito. Elas cederam espaços para servirem de dormitórios para os participantes de outros estados e de outras cidades sergipanas. Na ocasião havia uma greve de professores e professoras da rede estadual de ensino e os jovens participantes dividiram o espaço com as senhoras professoras (dado que a maioria era mulher). Quanto aos diretores e reitores, o contato foi agendado previamente e seguiu-se toda formalidade com ofícios, memorandos e termos de responsabilidade. 
Num caso e no outro, não era apenas uma relação de gênero que se fazia presente, mas um conflito intergeracional. Quando os membros jovens se dirigiam às instituições ou entidades, havia certas dificuldades que não davam conta, além de serem pouco creditados. Daí a necessidade da mediação de um professor, diretor da CCTECA e de uma professora, uma das responsáveis pelo projeto.

Toda a parte financeira do evento também ficou sob a responsabilidade de mulheres, tanto o dinheiro adquirido por meio do Programa de Apoio a Eventos no País (PAEP/Capes), projeto assinado por uma professora do IFS e membro da SEASE, quanto o dinheiro obtido com as inscrições. Todo o gerenciamento financeiro, portanto, foi feito por elas. Onde estavam os homens? Como a SEASE tem uma tesoureira, ela buscou o apoio de outras mulheres. Além disso, os homens mais velhos eram professores e estavam bastante atarefados como as atividades de docência, assim elas não podiam contar com eles. Os mais novos não inspiravam confiança no sentido de que conseguissem desempenhar-se melhor que elas.

$\mathrm{Na}$ segunda etapa, aconteceram as inscrições dos participantes e dos referidos trabalhos de pesquisa. O programa compreendeu oito palestras, dois minicursos, sessões de pôsteres e de comunicações. Toda a comissão científica era composta por homens. Uma aluna da graduação era a responsável por receber os trabalhos e repassar para os professores pesquisadores avaliarem. Depois disso, voltavam os trabalhos para a aluna e ela os agrupava em salas e horários. A confecção de folders também foi atribuída a uma aluna do curso de física, que não conseguiu se desincumbir da tarefa e então foi preciso a intervenção de um experto e, nesse caso, se recorreu a homens.

A terceira etapa foi a realização do evento propriamente dito. Em 4 de maio de 2015, às 17h30min iniciou-se o XV EANE, realizado no auditório da reitoria da UFS, Campus São Cristóvão - SE. Contou com a participação de astrônomos amadores e profissionais, estudantes e entusiastas da astronomia e astronáutica do nordeste e de outras regiões brasileiras. Todas as delegações que se fizeram presentes no evento eram dirigidas por homens. O conjunto de participantes era composto predominantemente por homens. Apenas uma mulher solicitou dormitório, por exemplo. 
Essa foi a etapa em que mais se contou com os trabalhos dos homens da SEASE. Um deles foi o cerimonialista, apresentava as palestras. A mesa de abertura era formada predominantemente por homens e apenas duas mulheres: a professora que assinou o projeto e a presidente da SEASE. Os rapazes se ocuparam também do transporte de objetos, móveis, alimentos etc. de um lugar para outro. Aqui a responsabilidade pelas tarefas foi dividida entre todos, inclusive, havendo problemas de última hora, recorria-se a duas mulheres, uma delas a professora do IFS, e a dois homens, um deles o professor da UFS.

\section{Considerações Finais}

O papel do/a cientista, do/a artista, do/a filósofo/a, do/a astrônomo/a é de espalhar o conhecimento para todos os cidadãos e cidadãs. Conforme Steiner (2006, p. 247), "a missão da astronomia é de nos dizer onde estamos, de onde viemos e para onde vamos". Pois bem, se essa missão pode até ser infinita, certamente ela possui vários começos e um deles foi a realização do $15^{\circ}$ EANE em Sergipe.

A sugestão de lidar com o desconhecido, com o distante é, por si só, excitante. Mas não é só isto que tem atraído mulheres à área da astronomia ou mesmo a se tornarem membros da SEASE. Todas elas, com exceção de uma, estudam ou almejam fazer curso da área de ciências exatas e isso sim as aproxima da astronomia. Elas estão próximas da matemática tanto quanto eles. Daí a importância de se aprender na escola que meninas são tão inteligentes e perspicazes em Matemática e em Física quanto os meninos (CARVALHO \& RABAY, 2013).

O evento mostrou que a ciência pode ser objeto de estudo de adultos e de jovens. A astronomia é uma ciência aberta a veteranos e principiantes. Havia no evento representantes da NASA e da Olimpíada Brasileira de Astronomia e Astronáutica (OBA), do Observatório Nacional (ON) e estudantes da graduação e do ensino médio. Por um lado, havia cientistas, escritores, detentores de títulos e ocupantes de altas hierarquias, mas por outro lado observadores amadores e jovens sonhadores acalentando o desejo de se tornarem astrônomos, astrofísicos, astronautas, cientistas, enfim, desbravadores dos céus. 
O evento mostrou que homens e mulheres inseridos no contexto científico dão respostas semelhantes no que diz respeito ao desejo de se tornarem cientistas e ao prazer de estudar. No evento não se disseminaram os estereótipos de que homem sabe mais matemática do que mulher. Mesmo tendo apenas uma mulher como palestrante, a leitura que meninos e meninas puderam fazer é a de que é possível mulheres estarem no topo da carreira acadêmica numa ciência como a astronomia. Na SEASE, a maioria das mulheres é muito boa em matemática e em conhecimentos astronômicos tanto quanto, ou mais do que, a maioria dos homens.

A SEASE vem demonstrando que a astronomia é um a ciência aberta a todos, adultos e jovens, amadores e cientistas, homens e mulheres. Os trabalhos desenvolvidos, ao longo desses anos, têm mostrado que quanto mais cedo o espírito científico cativar as crianças e os jovens menos tempo será empregado para se promover a inclusão e equidade de gênero nos estudos astronômicos.

\section{Referências}

AGRELLO, D. A. \& GARG, R. Mulheres na física: poder e preconceito nos países em desenvolvimento. Rev. Bras. Ensino Fís. [online]. 2009, vol.31, n.1, p. 1305.1-1305.6. ISSN 1806-9126.

AMARAL, P. O ensino de astronomia nas séries finais do ensino fundamental: uma proposta de material didático de apoio ao professor. 2008.102 f. Dissertação (Mestrado em Ensino de Ciências) - Universidade Nacional de Brasília, Brasília, 2008.

DOBSON, Andrea K.; BRACHER, Katherine. A Historical Introduction to Women in Astronomy. Mercury, v21 n1 p4-15 Jan-Feb 1992. Disponível: https://eric.ed.gov/?id=EJ447803. Acesso em julho de 2016.

CARVALHO, Maria Eulina. P. de. "Gênero e carreiras universitárias: o que mudou?" Trabalho apresentado no Seminário Internacional Fazendo Gênero 7. UFSC, 28 a 30 ago. 2006.

CARVALHO, Maria Eulina. P. de. \& RABAY Glória. Gênero e Educação Superior: apontamentos sobre o tema. João Pessoa: Editora UFPB, 2013. 
CESARSKY, Catherine \& WALKER, Helen. Head Count: Statistics about women. $\begin{array}{lllll}\text { Astronomy } & \& & \text { Geophysics, } & 2010, & 2.33-2.36 .\end{array}$ http://astrogeo.oxfordjournals.org/content/51/2/2.33.full.pdf+html. Acesso em 10 de junho de 2015.

CLAYTON, Geoffrey. Not Equal, Not Yet. In Astronomy. Mercury, v21 n1 p4-15 Jan-Feb 1992. Disponível: https://eric.ed.gov/?id=EJ447803. Acesso em julho de 2016.

GARCIA, Eloi $\quad$ S. $\quad$ Mulher $\quad$ e $\quad$ a Ciência. http://www.ioc.fiocruz.br/pages/informerede/corpo/noticia/2006/novembro/08_11_06_02.htm. Acesso em 10 de julho de 2015.

LANGHI, Rodolfo \& NARDI, Roberto. Ensino da astronomia no Brasil: educação formal, informal, não formal e divulgação científica. Revista Brasileira de Ensino de Física, v. 31, n. 4, 2009, 4402-11. http://www.sbfisica.org.br/rbef/pdf/314402.pdf. Acesso em 10 de julho de 2015.

LIMA, Betina Stefanello. O labirinto de cristal: as trajetórias das cientistas na física. In Estudos Feministas, Florianópolis, 21(3): 496, set.- dez./2013.

LOMBARDI, M. R. Perseverança e Resistência: A Engenharia como Profissão Feminina. 2005. 279 f. Tese (Doutorado em Educação) - Universidade de Campinas, Campinas-SP, 2005.

LOPES, R. Entrevista concedida ao programa ILHA FM em 4 de junho de 2015, às 18:00h. Aracaju, Sergipe.

MANNARINO, Remo. Harém de Pickering: mulheres geniais. Postado em 26 de outubro de 2011. http://ohomemhorizontal.blogspot.com.br/2007/06/harm-de-pickering.html. Acesso em 7 de junho de 2015 .

\section{MCDERMOTT, Maeve. "Pickering's Harem" - The Untold Story Of The Women Who Mapped Our Galaxy. Postado em 28 de abril de 2014. http://tvblogs.nationalgeographic.com/2014/04/28/pickerings-harem-the-untold-story-of-the- women-who-mapped-our-galaxy/. Acesso em 7 de junho de 2015.}

MELLO, D. Cutetalk com Duília de Mello, a astrônoma brasileira que arrasa na NASA. http://www.cutedrop.com.br/2015/04/cutetalk-com-duilia-de-mello-a-astronoma-brasileiraque-arrasa-na-nasa/. Acesso em 10 de junho de 2015.

OBA. Olimpíada Brasileira de Astronomia e Astronáutica. http://www.oba.org.br/site/. Acesso em 5 de junho de 2015. 
SCHIEBINGER, Londa. O Feminismo Mudou a Ciência? Trad. Raul Fiker. Bauru, SP: EDUSC, 2001, 384p.

SEASE. Estatuto da Sociedade de estudos astronômicos de Sergipe. Aracaju, 2011.

STEINER, J. E. Astronomia no Brasil. Ciência e Cultura. Vol. 61. São Paulo, 2009. on-line version ISSN 2317-6660. p. 45-49.

STEINER, J. E. A origem do universo. Estudos Avançados 20 (58), 2006. p. 232-248. http://www.scielo.br/pdf/ea/v20n58/20.pdf. Acesso em 1 de junho de 2015.

TROWER, Cathy. University and College Faculty. In HILL, C.; Corbett, C.; St. Rose, A. Why So Few? Women in Science, Technology, Engineering and Mathematics. AAUW, Washington, 2010.

VIEGAS, Sueli M. M. A astronomia brasileira no feminino. In História da Astronomia no Brasil - Volume II Oscar T. Matsuura (Org.) Recife: Cepe, 2014.

\title{
ASTRONOMY: AN EXPERIENCE IN WHICH WOMEN ARE PROTAGONISTS
}

\begin{abstract}
Astronomy is a science that accepts amateurs and professional researchers. In one way or another it has attracted more men than women in Brazil and worldwide. Its proximity to physics and mathematics explains, possibly, the great number of male adepts. But in Sergipe, the society of astronomical studies called SEASE has shown that astronomy can seduce women and make them scientists. At SEASE, they not only study but also hold leadership positions. Considering the importance of this science, this text offers a brief presentation of the pioneers in astronomy, and an account of the formation of SEASE and of the organization of one of the largest congresses of astronomy in the country, the 15th Meeting of Astronomy of the Northeast. It intends to show that when women and men have equal opportunities to learn and to enjoy mathematics, the former can choose a scientifictechnological career. It also intends to make visible women's stories of inclusion in scientific-technological careers in order to achieve gender equity in higher education institutions and research centers, especially in the hard sciences.
\end{abstract}

Keywords: Astronomy, Women, Leadership, Gender. 


\section{ASTRONOMÍA: UNA EXPERIENCIA EN QUE MUJERES ACTUAN COMO PROTAGONISTAS}

\section{RESUMEN}

La astronomía es una ciencia que reúne a investigadores aficionados y profesionales. Sea de una manera o de otra ha atraído a más hombres que mujeres en Brasil y en el mundo. Su aproximación a la física y las matemáticas explica, posiblemente, el gran número de seguidores masculinos. Sin embargo, en Sergipe, la sociedad de estudios astronómicos llamada SEASE ha demostrado que la astronomía puede seducir a las mujeres y convertirlas en científicas. En la SEASE, son estudiosas y también ocupan posiciones de liderazgo. Considerando la importancia de esa ciencia, este texto ofrece una breve presentación de las pioneras en la astronomía, y un relato de la formación de SEASE y de la organización de una de las mayores conferencias de astronomía del país, la $15^{\mathrm{a}}$ Reunión de Astronomía del Noreste. Así, pretende mostrar que cuando las mujeres y los hombres tienen las mismas oportunidades de aprender y disfrutar de las matemáticas, ellas pueden elegir una carrera científica y tecnológica. Tiene la intención también de visibilizar historias de mujeres insertadas en las carreras científicas y tecnológicas con el fin de lograr la equidad de género en las instituciones de educación superior e instituciones de investigación, especialmente en las ciencias duras.

Palabras clave: Astronomía, Mujeres, Liderazgo, Género.

Recebido em 11 de maio de 2018 e aprovado para publicação em 12 de agosto de 2018. 